\title{
Antibiofilm and Anti-Inflammatory Activities of Houttuynia cordata Decoction for Oral Care
}

\author{
Yasuko Sekita, ${ }^{1}$ Keiji Murakami, ${ }^{2}$ Hiromichi Yumoto, ${ }^{3}$ Kouji Hirao, ${ }^{3}$ \\ Takashi Amoh, ${ }^{2}$ Natsumi Fujiwara, ${ }^{2}$ Katsuhiko Hirota, ${ }^{2}$ Hideki Fujii, ${ }^{2}$ Takashi Matsuo, ${ }^{3}$ \\ Yoichiro Miyake, ${ }^{2}$ and Yoshiki Kashiwada ${ }^{1}$ \\ ${ }^{1}$ Department of Pharmacognosy, Institute of Biomedical Sciences, Tokushima University Graduate School, Tokushima 770-8505, Japan \\ ${ }^{2}$ Department of Oral Microbiology, Institute of Biomedical Sciences, Tokushima University Graduate School, \\ Tokushima 770-8504, Japan \\ ${ }^{3}$ Department of Conservative Dentistry, Institute of Biomedical Sciences, Tokushima University Graduate School, \\ Tokushima 770-8504, Japan
}

Correspondence should be addressed to Keiji Murakami; kmurakami@tokushima-u.ac.jp

Received 29 March 2017; Revised 23 July 2017; Accepted 10 September 2017; Published 16 October 2017

Academic Editor: Subash C. Gupta

Copyright ( 2017 Yasuko Sekita et al. This is an open access article distributed under the Creative Commons Attribution License, which permits unrestricted use, distribution, and reproduction in any medium, provided the original work is properly cited.

\begin{abstract}
Dental biofilms that form in the oral cavity play a critical role in the pathogenesis of several infectious oral diseases, including dental caries, periodontal disease, and oral candidiasis. Houttuynia cordata (HC, Saururaceae) is a widely used traditional medicine, for both internal and external application. A decoction of dried $\mathrm{HC}$ leaves ( $\mathrm{dHC}$ ) has long been consumed as a healthpromoting herbal tea in Japan. We have recently reported that a water solution of HC poultice ethanol extract (wHCP) exerts antimicrobial and antibiofilm effects against several important oral pathogens. It also exhibits anti-inflammatory effects on human keratinocytes. In our current study, we examined the effects of dHC on infectious oral pathogens and inflammation. Our results demonstrated that dHC exerts moderate antimicrobial effects against methicillin-resistant Staphylococcus aureus (MRSA) and other oral microorganisms. dHC also exhibited antibiofilm effects against MRSA, Fusobacterium nucleatum (involved in dental plaque formation), and Candida albicans and inhibitory effects on interleukin-8, CCL20, IP-10, and GRO $\alpha$ productions by human oral keratinocytes stimulated by Porphyromonas gingivalis lipopolysaccharide (a cause of periodontal disease), without cytotoxic effects. This suggests that $\mathrm{dHC}$ exhibits multiple activities in microorganisms and host cells. dHC can be easily prepared and may be effective in preventing infectious oral diseases.
\end{abstract}

\section{Introduction}

Dental biofilms that form in the oral cavity play a critical role in the pathogenesis of numerous infectious oral diseases, including periodontal disease. This can be due to the absorption of antimicrobial and antiseptic drugs and development of resistance to host immune cells [1-3]. Predominant fungi such as Candida albicans in the oral cavity can also contribute to the development of infectious oral diseases ranging from denture stomatitis $[4,5]$ to life-threatening invasive infections, including aspiration pneumonia. This is particularly apparent in immunocompromised and elderly patients [6-8]. We have previously reported a higher prevalence of Candida spp., Pseudomonas aeruginosa, and Staphylococcus spp. in the oropharyngeal microflora of patients with cerebrovascular infarction and dysphagia [6]. Reducing adherence and biofilm formation by oral microorganisms can contribute to the prevention of chronic oral infections that may lead to potentially severe, systemic opportunistic diseases, particularly in the elderly $[9,10]$.

Oral keratinocytes play an important role as the first physical barrier to bacterial invasion by organizing the local innate immune system against colonizing microorganisms. They also secrete several proinflammatory mediators (i.e., chemokines and cytokines) in response to various stimuli, including microbial infections and chemical or thermal 
irritations [11-13]. These mediators ultimately cause periodontal inflammation. Lipopolysaccharide (LPS) from Gramnegative bacteria, such as the important periodontal pathogen Porphyromonas gingivalis, upregulates the production of various proinflammatory mediators via signal cascades in the gingival epithelium. These include interleukin-8 (IL8), CCL20, IFN- $\gamma$-inducible protein 10 (IP-10), and growth related oncogene- $\alpha(\mathrm{GRO} \alpha)$ [14-22]. Therefore, the development of oral care products that reduce biofilm formation and subsequent proinflammatory responses is essential for improving health and preventing disease.

Previous studies have demonstrated that extracts from medicinal plants exhibit various pharmacological activities including antimicrobial effects [23-26], antiadherence effects against oral microorganisms [27-29], and anti-inflammatory effects [30-33]. Houttuynia cordata Thunb. (HC, Saururaceae) is widely used as a traditional medicine, both internally and externally [34]. However, evidence to indicate that HC extract exerts pharmacological effects against oral microorganisms is limited. We have focused on identifying and characterizing any activity of HC against infectious diseases caused by oral microorganisms. We have recently reported that a $\mathrm{HC}$ poultice ethanol extract (eHCP) exerted antibacterial effects against cutaneous infection-related bacteria and anti-inflammatory effects on human keratinocytes [34]. However, caution is required when suggesting that eHCP could be applied to oral care because ethanol found in mouthwashes has been suggested to increase the risk of oral cancer [35].

Fortunately, we have also shown that a water solution of eHCP (wHCP) exhibits antimicrobial and antibiofilm effects on oral microorganisms and anti-inflammatory effects on oral keratinocytes [36]. A decoction of dried HC leaves (dHC), commonly consumed as a health-promoting herbal tea in Japan, is simpler to prepare than wHCP. We therefore examined the antimicrobial and antibiofilm effects of $\mathrm{dHC}$ on several important infectious oral pathogens and investigated the anti-inflammatory effects of $\mathrm{dHC}$ on $P$. gingivalis LPSstimulated human oral keratinocytes.

\section{Material and Methods}

2.1. Plant Materials and Sample Preparation. HC used in this study was collected in Kochi City and identified by Dr. K. Fujikawa (the Kochi Prefectural Makino Botanical Garden, Kochi, Japan). Voucher specimens (FOS-007536, FOS-007537, and FOS-010389) were also deposited here.

2.2. Preparation of $d H C$. $\mathrm{dHC}$ was prepared as follows: $3 \mathrm{~g}$ of dried HC leaves was decocted with $130 \mathrm{~mL}$ of sterile purified water at $90-95^{\circ} \mathrm{C}$ for $30 \mathrm{~min}$ (EK-SA 10, ZOJIRUSHI, Osaka, Japan). The decoction was then centrifuged for $15 \mathrm{~min}$ at $1,500 \times \mathrm{g}$. After centrifugation, the clear supernatant layer was filtered through a $0.45-\mu \mathrm{m}$ filter and stored at $4^{\circ} \mathrm{C}$ until being assayed.

2.3. Flavonoid Glycosides. Quercitrin and rutin were purchased from Sigma-Aldrich (St. Louis, MO) and Tokyo Chemical Industry Co., Ltd. (Tokyo, Japan), respectively.
TABLE 1: Bacterial strains.

\begin{tabular}{lc}
\hline Strain & Source \\
\hline Methicillin-resistant Staphylococcus aureus T31 & Clinical isolate \\
Methicillin-resistant Staphylococcus aureus COL & Wild type \\
Streptococcus mutans MT8148 & Clinical isolate \\
Streptococcus mutans UA159 & Clinical isolate \\
Streptococcus sobrinus 1310 & Clinical isolate \\
Streptococcus gordonii ATCC10558 & Type strain \\
Streptococcus oralis ATCC10557 & Type strain \\
Streptococcus constellatus 4528 & Clinical isolate \\
Streptococcus intermedius 40138 & Clinical isolate \\
Streptococcus mitis JCM 12971 & Wild type \\
Aggregatibacter actinomycetemcomitans Y4 & Wild type \\
Fusobacterium nucleatum JCM8532 & Wild type \\
Porphyromonas gingivalis ATCC33277 & Type strain \\
Pseudomonas aeruginosa PAO1 & Wild type \\
Candida albicans CAD1 & Clinical isolate \\
\hline
\end{tabular}

Isoquercitrin and hyperin were isolated from the aerial parts of Hypericum sikokumountanum [37]. Flavonoid glycosides were dissolved in dimethyl sulfoxide (DMSO, nacalai tesque, Kyoto, Japan).

2.4. Bacterial Strains and Growth Conditions. The bacterial strains used in this study are shown in Table 1. $P$. aeruginosa was grown in Muller-Hinton broth (Becton Dickinson, Sparks, MD, USA) that was supplemented with $50 \mu \mathrm{g} / \mathrm{mL} \mathrm{CaCl}_{2}$ and $25 \mu \mathrm{g} / \mathrm{mL} \mathrm{MgCl}_{2}$. Methicillin-resistant Staphylococcus aureus (MRSA) strains were grown in MullerHinton broth supplemented with $25 \mu \mathrm{g} / \mathrm{mL} \mathrm{CaCl}_{2}, 12.5 \mu \mathrm{g} /$ $\mathrm{mL} \mathrm{MgCl}_{2}$, and $2 \% \mathrm{NaCl}$ [38]. Streptococcus spp. were grown anaerobically in brain heart infusion (Becton Dickinson). Fusobacterium nucleatum and $P$. gingivalis were grown anaerobically in brain heart infusion supplemented with $5 \mu \mathrm{g} / \mathrm{mL}$ hemin and $0.5 \mu \mathrm{g} / \mathrm{mL}$ menadione. Aggregatibacter actinomycetemcomitans was grown anaerobically in Todd Hewitt Broth (OXOID Ltd., Hampshire, UK). C. albicans was grown in Sabouraud dextrose medium composed of $10 \mathrm{~g} / \mathrm{L}$ peptone and $40 \mathrm{~g} / \mathrm{L}$ glucose. For biofilm formation assays, trypticase soy broth (Becton Dickinson) supplemented with $5 \mu \mathrm{g} / \mathrm{mL}$ hemin and $0.5 \mu \mathrm{g} / \mathrm{mL}$ menadione, trypticase soy broth supplemented with $0.3 \%$ glucose, and yeast nitrogen base medium at $\mathrm{pH} 7$ containing $2.5 \mathrm{mmol} / \mathrm{L} \mathrm{N}$-acetylglucosamine [39] were used for F. nucleatum, MRSA-T31, and C. albicans, respectively.

2.5. Susceptibility Assay. The minimum inhibitory concentration (MIC) of dHC was assessed using a microbial broth dilution method. Approximately $10^{6}$ colony-forming units $(\mathrm{CFU}) / \mathrm{mL}$ of each bacterial culture were inoculated into $100 \mu \mathrm{L}$ of medium containing a twofold serial dilution of dHC in 96-well plates (TPP, Trasadingen, Switzerland) and incubated either anaerobically (for Streptococcus spp., A. actinomycetemcomitans, F. nucleatum, and $P$. gingivalis) or aerobically (for MRSA T31, MRSA COL, P. aeruginosa, and C. albicans) at $37^{\circ} \mathrm{C}$ for 20 or $48 \mathrm{~h}$. The MIC was 
defined as the lowest concentration that showed no bacterial growth.

2.6. Biofilm Formation Assay. A crystal violet biofilm assay was performed to quantify the biofilm mass as previously described [40]. A $2-\mu \mathrm{L}\left(10^{7} \mathrm{CFU} / \mathrm{mL}\right)$ sample of MRSA T31 or C. albicans CAD1 in the stationary phase or a 5$\mu \mathrm{L}\left(10^{7} \mathrm{CFU} / \mathrm{mL}\right)$ sample of F. nucleatum JCM8532 in the stationary phase was transferred into a 96-well plate (Cellstar, Greiner Bio-One, Frickenhausen, Germany) from the primary $150 \mu \mathrm{L}$ suspensions of broth or media. dHC was then added to a final concentration of $10 \%$. Quercitrin, isoquercitrin, hyperin, and rutin were added to a final concentration of $200 \mu \mathrm{g} / \mathrm{mL}$. Bacterial suspensions were incubated either anaerobically (for F. nucleatum) at $37^{\circ} \mathrm{C}$ for $24 \mathrm{~h}$ or aerobically (for MRSA T31 and C. albicans) at $37^{\circ} \mathrm{C}$ for 6 and $24 \mathrm{~h}$. For the positive control, 2 or $1 \mu \mathrm{g} / \mathrm{mL}$ of cetylpyridinium chloride (CPC) (Tokyo Chemical Industry Co., Ltd., Tokyo, Japan) was used [41]. For the negative control, 10\% distilled $\mathrm{H}_{2} \mathrm{O}$ was used. After incubation, any biofilms that formed were washed with purified water twice without disturbing the adherent biofilm. They were then stained with $150 \mu \mathrm{L}$ of $0.1 \%$ crystal violet at $25^{\circ} \mathrm{C}$ for $10 \mathrm{~min}$. Excess staining was removed by gentle washing with purified water. After drying, stained biofilms were extracted from each well by adding $150 \mu \mathrm{L}$ of ethanol, and the absorbance of the extract from the stained biofilm was measured at $595 \mathrm{~nm}$ using a microplate reader (model 680; Bio-Rad Laboratories, Hercules, CA, USA).

2.7. Cell Culture. RT-7 cells, an immortalized human keratinocyte cell line kindly provided by Dr. Kamata (Hiroshima University, Hiroshima, Japan) [42], were cultured in Keratinocyte-SFM (Gibco BRL, Gaithersburg, MD, USA) supplemented with $100 \mathrm{U} / \mathrm{mL}$ penicillin and $100 \mu \mathrm{g} / \mathrm{mL}$ streptomycin (Gibco BRL), at $37^{\circ} \mathrm{C}$ in a water-saturated atmosphere of $95 \%$ air and $5 \% \mathrm{CO}_{2}$. Confluent monolayers were cultured with $1 \mu \mathrm{g} / \mathrm{mL} P$. gingivalis LPS (InvivoGen, San Diego, CA, USA), with and without the addition of $1 \% \mathrm{dHC}$ or $50 \mu \mathrm{g} / \mathrm{mL}$ of quercitrin, isoquercitrin, hyperin, or rutin.

2.8. Lactate Dehydrogenase $(\mathrm{LDH})$ Cytotoxicity Assay. The effects of $\mathrm{dHC}$ on cell cytotoxicity were assessed using a LDH assay. Confluent RT-7 cell monolayers in a 24-well plate were cultured in Keratinocyte-SFM medium supplemented with $10 \%$ and $1 \% \mathrm{dHC}$ at $37^{\circ} \mathrm{C}$ for $24 \mathrm{~h}$ in a water-saturated atmosphere of $95 \%$ air and $5 \% \mathrm{CO}_{2}$. As a positive control, RT-7 cells were treated with $0.1 \%$ Triton X-100 at $25^{\circ} \mathrm{C}$ for $10 \mathrm{~min}$. In the cytotoxicity assay, the levels of $\mathrm{LDH}$ released into the recovered cell culture supernatants were measured using an LDH cytotoxicity assay kit (Cayman Chemical, Ann Arbor, MI, USA) following the manufacturer's instructions. Absorbance was measured at $490 \mathrm{~nm}$ using a microplate reader (Bio-Rad Laboratories).

2.9. Enzyme-Linked Immunosorbent Assay. Enzyme-linked immunosorbent assay (ELISA) kits were used to quantify the levels of IL-8, CCL20, IP-10, and GRO $\alpha$ (R\&D Systems, Minneapolis, MN, USA) in cell culture supernatants.
TABLE 2: MIC of dHC.

\begin{tabular}{lcc}
\hline Bacterial strain & \multicolumn{2}{c}{ MIC } \\
& $(\%)^{*}$ & $(\mu \mathrm{g} / \mathrm{mL})$ \\
\hline Methicillin-resistant Staphylococcus aureus T31 & 5 & 750 \\
Methicillin-resistant Staphylococcus aureus COL & 10 & 1500 \\
Streptococcus mutans MT8148 & $>10$ & $>1500$ \\
Streptococcus mutans UA159 & $>10$ & $>1500$ \\
Streptococcus sobrinus 1310 & $>10$ & $>1500$ \\
Streptococcus gordonii ATCC10558 & $>10$ & $>1500$ \\
Streptococcus oralis ATCC10557 & $>10$ & $>1500$ \\
Streptococcus constellatus 4528 & $>10$ & $>1500$ \\
Streptococcus intermedius 40138 & 10 & 1500 \\
Streptococcus mitis JCM 12921 & 10 & 1500 \\
Aggregatibacter actinomycetemcomitans Y4 & $>10$ & $>1500$ \\
Fusobacterium nucleatum JCM8532 & 2.5 & 375 \\
Porphyromonas gingivalis ATCC33277 & 10 & 1500 \\
Pseudomonas aeruginosa PAO1 & $>10$ & $>1500$ \\
Candida albicans CAD1 & $>10$ & $>1500$ \\
\hline
\end{tabular}

${ }^{*}$ Concentration of $\mathrm{dHC}$ in medium $\mathrm{v} / \mathrm{v}$.

2.10. Statistical Analysis. All statistical analyses were performed using an unpaired Student's $t$-test. Differences were considered significant when the probability value was less than $5 \%\left({ }^{*} P<0.05\right)$.

\section{Results}

3.1. Moderate Antimicrobial Effects of $d H C$. We examined the antimicrobial effects of dHC against several oral microorganisms. As shown in Table 2, dHC exerted a moderate antimicrobial effect against MRSA T31, MRSA COL, $S$. intermedius, S. mitis, F. nucleatum, and P. gingivalis (MIC; $375-1500 \mu \mathrm{g} / \mathrm{mL})$.

3.2. Antibiofilm Effects of $d H C$. We next investigated whether $\mathrm{dHC}$ had any antibiofilm effects. In this experiment, we used a culture of the MRSA T31 clinical isolate. This strain was selected because MRSA T31 exhibits increased biofilm formation compared to MRSA COL (data not shown). We also examined $F$. nucleatum and $C$. albicans. Both of these species form biofilms in the human oral cavity, including on denture surfaces $[43,44]$. A biofilm formation assay at 6 and $24 \mathrm{~h}$ revealed that $10 \% \mathrm{dHC}$ significantly inhibited biofilm formation by MRSA T31 (Figure 1(a)) and C. albicans (Figure $1(\mathrm{~b})$ ). We also showed that $10 \% \mathrm{dHC}$ significantly inhibited 24-h biofilm formation by $F$. nucleatum (Figure $1(\mathrm{c})$ ). In each experiment, $10 \% \mathrm{dHC}$ did not affect the growth of these microorganisms (data not shown). These results revealed that $\mathrm{dHC}$ exhibits an antibiofilm effect against MRSA T31, F. nucleatum, and C. albicans. However, $\mathrm{dHC}$ did not exert any antibiofilm effects against $S$. mutans MT8148, a cause of dental caries (data not shown). The MICs of dHC against MRSA T31, F. nucleatum, and C. albicans were $5 \%(750 \mu \mathrm{g} / \mathrm{mL}), 2.5 \%(375 \mu \mathrm{g} / \mathrm{mL})$, and $>10 \%$ $(>1500 \mu \mathrm{g} / \mathrm{mL})$, respectively. In the biofilm formation assay, bacterial abundance was approximately 100 -fold higher than 


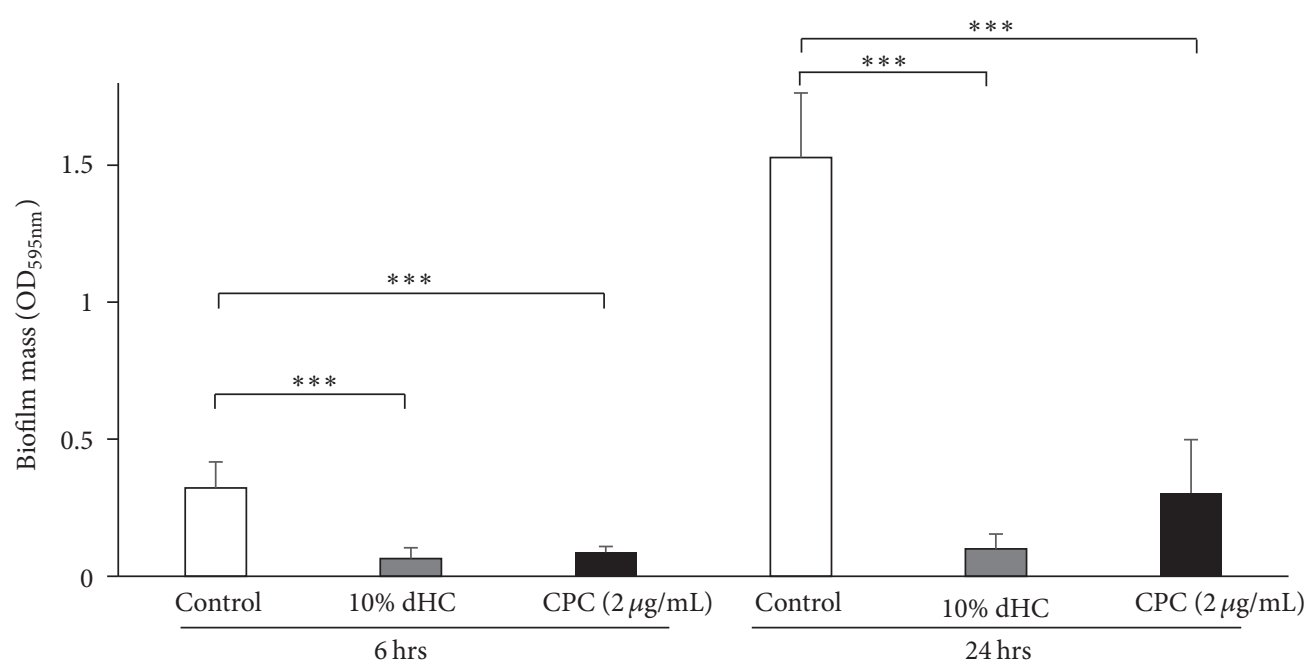

(a)

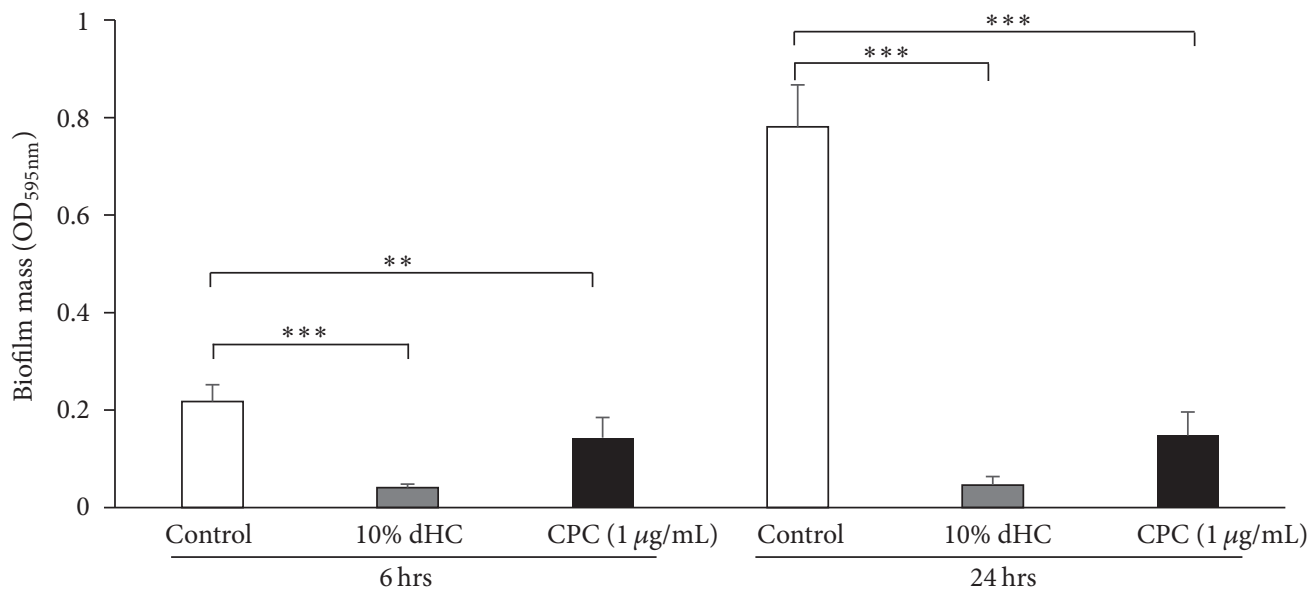

(b)

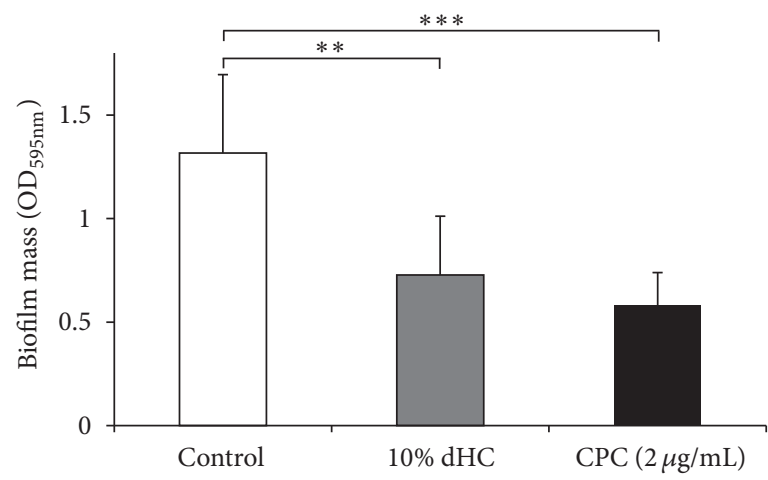

(c)

Figure 1: Antibiofilm effects of dHC on MRSA T31, C. albicans, and F. nucleatum. Antibiofilm effects of a water decoction of Houttuynia cordata (dHC) on biofilm formation by MRSA T31 (a) and CAD1 (b) at 6 or $24 \mathrm{~h}$. Antibiofilm effects of dHC on biofilm formation by F. nucleatum JCM8532 (c) at $24 \mathrm{~h}$. As a positive control, $2 \mu \mathrm{g} / \mathrm{mL}$ (for MRSA T31, F. nucleatum) or $1 \mu \mathrm{g} / \mathrm{mL}$ (for CAD1) of cetylpyridinium chloride (CPC) was used. A negative control of $10 \%$ distilled $\mathrm{H}_{2} \mathrm{O}$ was used. ${ }^{* * * *}$ Significant differences between the indicated groups at $p<0.001 .{ }^{* *}$ Significant differences between the indicated groups at $p<0.01$ using a Student's $t$-test $(n=8)$. 
TABLE 3: MIC of flavonoid glycosides.

\begin{tabular}{|c|c|c|c|c|}
\hline \multirow{2}{*}{ Bacterial strain } & \multicolumn{4}{|c|}{$\mathrm{MIC}(\mu \mathrm{g} / \mathrm{mL})$} \\
\hline & Quercitrin & Isoquercitrin & Hyperin & Rutin \\
\hline Methicillin-resistant Staphylococcus aureus T31 & $>512$ & $>512$ & $>512$ & $>512$ \\
\hline Candida albicans CAD1 & $>512$ & $>512$ & $>512$ & $>512$ \\
\hline Fusobacterium nucleatum JCM8532 & 256 & 512 & 512 & 256 \\
\hline
\end{tabular}

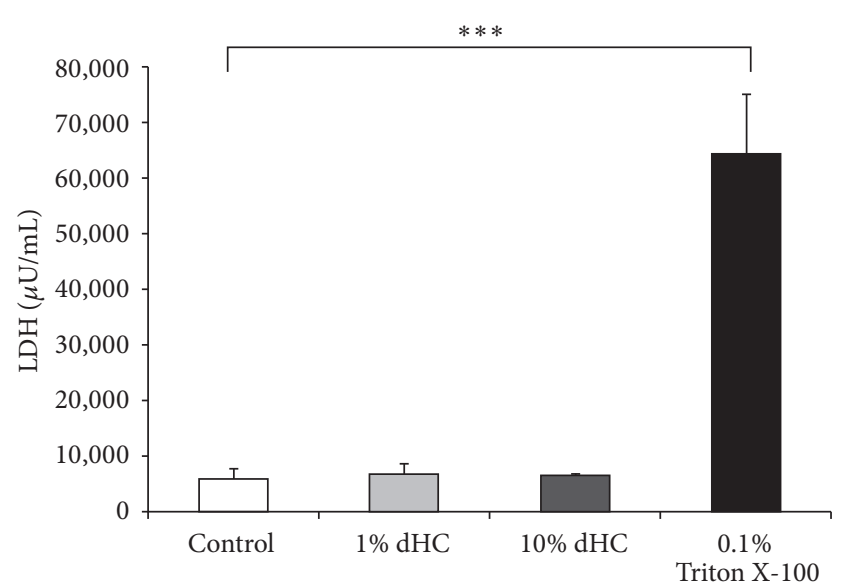

FIGURE 2: No cytotoxic effects of $d H C$ on oral keratinocytes. The cytotoxic effects of $\mathrm{dHC}$ on RT-7 cells were assessed by a lactate dehydrogenase (LDH) cytotoxicity assay. 0.1\% Triton X-100 treatment and gentle agitation at $25^{\circ} \mathrm{C}$ for $10 \mathrm{~min}$ were used as a positive control. ${ }^{* * *}$ Significant differences between the indicated groups at $p<0.001$ using a Student's $t$-test $(n=4)$.

that in the MIC assay. We also observed that bacteria grew despite high concentrations of $\mathrm{dHC}$.

3.3. No Cytotoxic Effects of dHC on Oral Keratinocytes. To investigate the cytotoxicity of $\mathrm{dHC}$ on oral keratinocytes, we measured the levels of LDH released from RT-7 cells. As shown in Figure 2, dHC did not exert any cytotoxic effects, up to a concentration of $10 \%$. These results suggest that $\mathrm{dHC}$ could be applied to oral care.

3.4. Inhibitory Effects of $\mathrm{dHC}$ on Chemokine Production by Oral Keratinocytes. We have previously demonstrated that CCL20 produced by inflamed gingival epithelial cells appears to be closely connected to the proinflammatory response of the gingiva. This is due to an important regulatory role in specific lymphocyte migration into diseased periodontal tissue [15]. In addition, TLR2, a pattern recognition receptor for LPS from Gram-negative bacteria such as $P$. gingivalis, is strongly expressed in the pocket epithelium of periodontal tissues with chronic periodontitis. This participates in a signaling cascade that upregulates the production of IL-8, IP-10, and GRO $\alpha[12,14,16-22,45]$. We therefore examined whether dHC inhibits the production of IL-8, CCL20, IP-10, and GRO $\alpha$ in RT-7 cells stimulated by P. gingivalis LPS. We found that $1 \% \mathrm{dHC}$ significantly inhibited IL-8, CCL20, IP10 , and GRO $\alpha$ productions by RT-7 cells stimulated with $P$. gingivalis LPS after $24 \mathrm{~h}$ (Figures 3(a), 3(b), 3(c), and 3(d)).
This suggests that $\mathrm{dHC}$ may be clinically useful as an oral care product to prevent the infectious oral inflammation that is observed during periodontal disease.

3.5. Antibiofilm and Anti-Inflammatory Effects of Flavonoid Glycosides. Previous reports have shown that the leaves of $\mathrm{HC}$ contain flavonoid glycosides such as quercitrin, isoquercitrin, hyperin, and rutin $[46,47]$. In this study, antibacterial, antibiofilm, and anti-inflammatory assays of four flavonoid glycosides (quercitrin, isoquercitrin, hyperin, and rutin) were performed. As shown in Table 3, these flavonoid glycosides had little antibacterial activities. However, $200 \mu \mathrm{g} / \mathrm{mL}$ of quercitrin, isoquercitrin, and hyperin significantly inhibited 24-h biofilm formation by MRSA T31 and $F$. nucleatum but rutin showed inhibitory effect of biofilm formation only by MRSA T31 (Figures 4(a) and 4(c)). In biofilm formation by $C$. albicans, we could not observe antibiofilm effects by these flavonoid glycosides (Figure 4(b)). Moreover, $50 \mu \mathrm{g} / \mathrm{mL}$ of quercitrin, isoquercitrin, hyperin, and rutin significantly inhibited CCL20, IP-10, and GRO $\alpha$ productions by RT-7 cells stimulated with $P$. gingivalis LPS (Figures 5(b), 5(c), and 5(d)). In IL-8 production, suppressive effect was observed only in rutin (Figure 5(a)).

\section{Discussion}

Our study has successfully demonstrated that dHC exerts a moderate antimicrobial effect against microorganisms that normally colonize the oral cavity (Table 2). We have also shown that $\mathrm{dHC}$ exhibits antibiofilm effects against MRSA, F. nucleatum, and C. albicans (Figures 1(a), 1(b), and 1(c)). Finally, we have shown that dHC can inhibit IL-8 and CCL20 production by $P$. gingivalis LPS-stimulated human oral keratinocytes, with no apparent cytotoxic effects (Figures 2, 3(a), 3(b), 3(c), and 3(d)).

Previous studies have reported that medicinal plant extracts can exert moderate antimicrobial effects against oral microorganisms. These include a crude aqueous extract of ripe Morinda citrifolia fruit (Indian noni), a methanol extract of Polygonum cuspidatum, and a methanol extract of Syzygium aromaticum (clove) [23-26]. However, it has been suggested that the use of organic extracts that include ethanol for oral care increases the risks of adverse reactions [35]. Therefore, a water solution of HC poultice ethanol extract (wHCP) used in our study may be safer than the ethanol based extract (eHCP) [36]. Our study has examined the properties of $\mathrm{dHC}$, which is simpler to prepare than wHCP and has been used as health-promoting herbal tea without any reported adverse reactions from our interview survey $[34,36]$. Previous studies have demonstrated that medicinal 


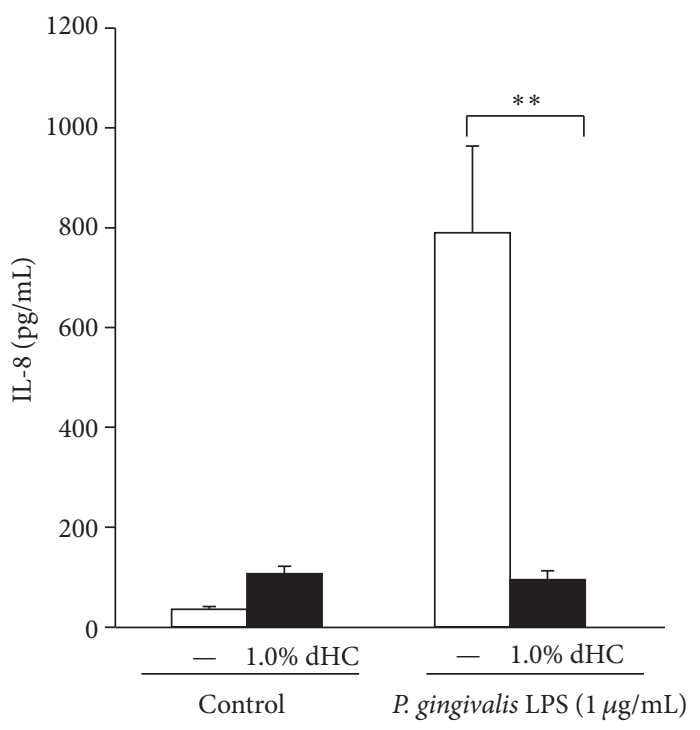

(a)

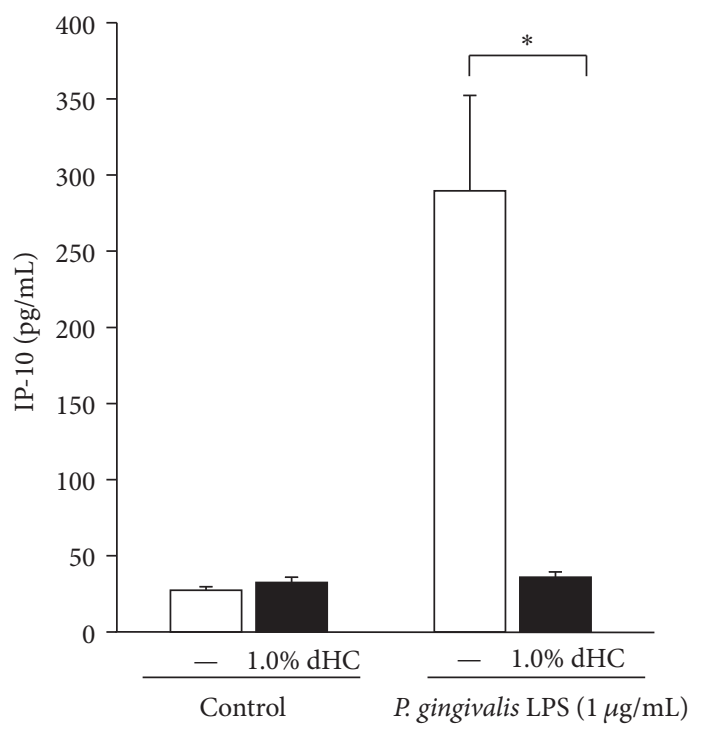

(c)

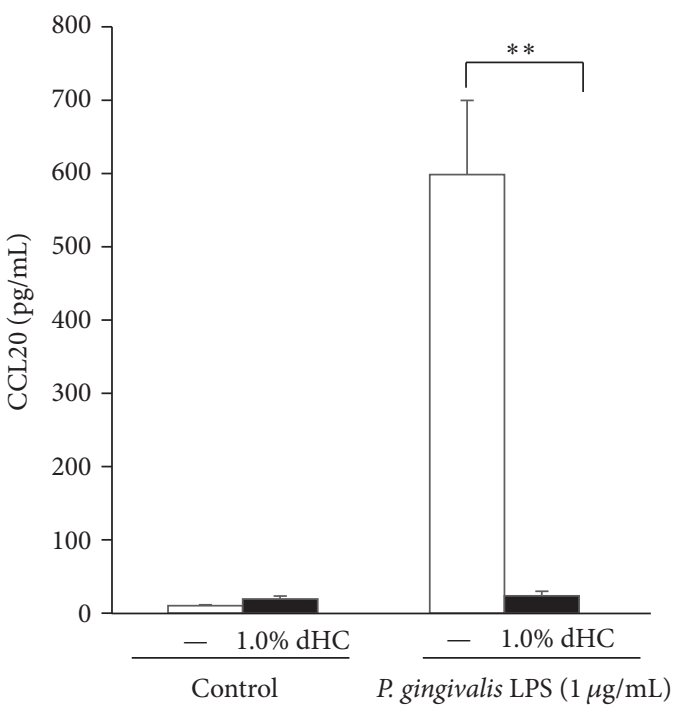

(b)

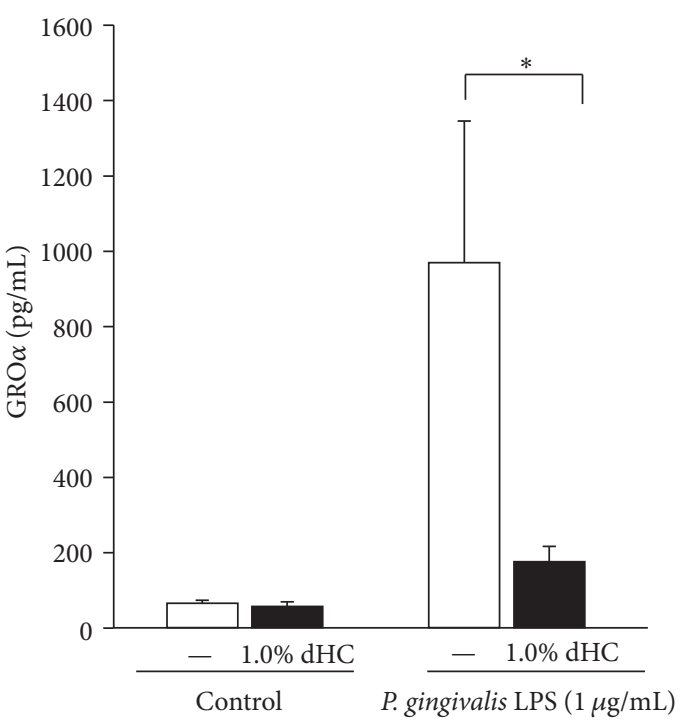

(d)

FIGURE 3: Inhibitory effects of $\mathrm{dHC}$ on chemokine production by P. gingivalis LPS-stimulated oral keratinocytes. Inhibitory effects of a water decoction of Houttuynia cordata (dHC) on IL-8 (a), CCL20 (b), IP-10 (c), and GRO $\alpha$ (d) production by oral keratinocytes stimulated with $P$. gingivalis LPS for $24 \mathrm{~h} .{ }^{* *}$ Significant differences between the indicated groups at $p<0.01$. ${ }^{*}$ Significant differences between the indicated groups at $p<0.05$ using a Student's $t$-test $(n=6)$.

plants also exert antiadherence effects against oral microorganisms [27-29]. In addition to a moderate antimicrobial effect, our results have shown that dHC significantly inhibits adherence after $6 \mathrm{~h}$ (Figures 1(a) and 1(b)) and biofilm formation by MRSA and C. albicans at $24 \mathrm{~h}$ (Figures 1 (a) and 1 (b)). It also inhibited biofilm formation by F. nucleatum (Figure 1(c)).

Finally, HC has also been shown to have an effect on host responses, with previous studies reporting that a $70 \%$ ethanol extract of HC dried aerial parts inhibits the production of several inflammatory biomarkers by lung epithelial cells, including IL-6 and nitric oxide (NO), and $\mathrm{HC}$ also inhibited lung inflammatory responses in a mouse model of LPSinduced acute lung injury [32]. Furthermore, a HC ethanol extract reduced the production of proinflammatory cytokines through the NF- $\kappa$ B signaling pathway in human mast cells [31]. A water extract of $\mathrm{HC}$ has also been shown to exert strong anti-inflammatory effects against $S$. aureus lipoteichoic acid-induced inflammatory responses that are partly attributed to the inhibition of tumor necrosis factor (TNF) expression in dermal fibroblasts [30]. Finally, a powdered extract of $\mathrm{HC}$ was recently found to modulate innate oral immune mediators in oral epithelial cells [33], and the mRNA abundance of IL-8 and CCL20 (used as inflammatory mediators) was upregulated in a dose-dependent manner. However, our results demonstrated that dHC inhibited IL-8, CCL20, IP-10, and GRO $\alpha$ production by P. gingivalis LPS-stimulated 


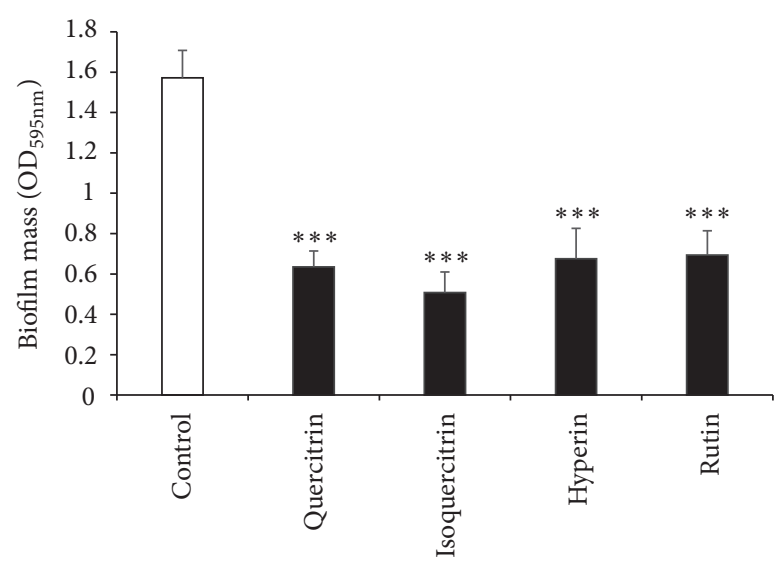

(a)

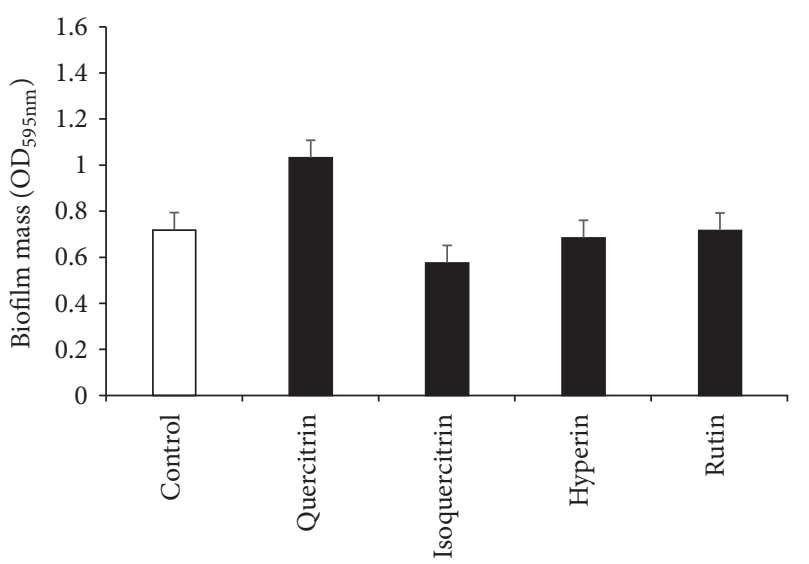

(b)

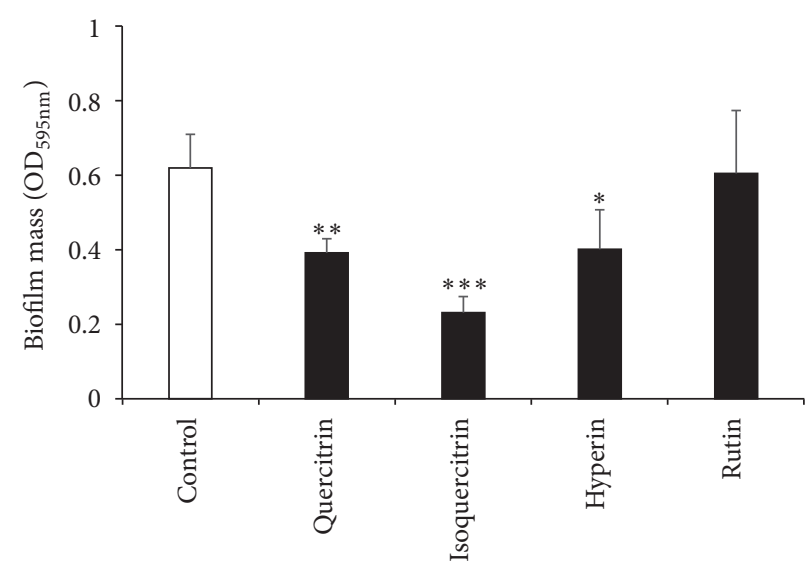

(c)

Figure 4: Antibiofilm effects of flavonoid glycosides on MRSA T31, C. albicans, and F. nucleatum. Antibiofilm effects of flavonoid glycosides on biofilm formation by MRSA T31 (a), CAD1 (b), and F. nucleatum (c) at 24-h. A negative control of $2 \%$ DMSO was used. ${ }^{* * *}$ Significant differences between the indicated groups at $p<0.001 .{ }^{* *}$ Significant differences between the indicated groups at $p<0.01$. ${ }^{*}$ Significant differences between the indicated groups at $p<0.05$ using a Student's $t$-test $(n=4)$.

human oral keratinocytes. This indicates that $\mathrm{dHC}$ can exhibit multiple different activities against microorganisms and host cells and may be useful as an oral care product to prevent infectious oral diseases.

Previous reports have shown that HC contains aldehydes, such as capric aldehyde (decanal), lauryl aldehyde (dodecanal), and decanoyl acetaldehyde (3-oxo-dodecanal, houttuynin), and flavonoid glycosides, such as quercitrin, isoquercitrin, hyperin, and rutin [46-49]. Aldehydes have antibacterial activity; however, the dried leaves of HC could not contain aldehydes because of their instability and volatility. This will be why the antimicrobial effects of $\mathrm{dHC}$ were weaker than those of wHCP. Conversely, the antibiofilm and antiinflammatory effects demonstrated by $\mathrm{dHC}$ were similar to those of wHCP. This suggests that the antibiofilm and antiinflammatory constituents of $\mathrm{dHC}$ and $\mathrm{wHCP}$ would be flavonoid glycosides. These effects of each flavonoid glycoside are different with bacterial species and cytokines. The use of dHC containing flavonoid glycosides represents a simpler preparation method than wHCP for self-medication.

In Japan, aspiration pneumonia is a serious medical issue in immunocompromised patients, particularly the elderly.
We have previously reported a higher prevalence of Candida spp., P. aeruginosa, and Staphylococcus spp. in the oropharyngeal microflora of patients with cerebrovascular infarction and dysphagia [6]. Reducing adherence and biofilm formation by oral microorganisms can contribute to the prevention of chronic oral infections and potentially severe, systematic opportunistic diseases, particularly in the elderly $[9,10]$. Therefore, the use of dHC as herbal tea may strongly contribute to the prevention of aspiration pneumonia.

Povidone iodine, chlorhexidine, and benzethonium chloride are typically used as antiseptic mouthwashes or rinses to prevent oral infections including dental caries and periodontal diseases [50-55]. However, these antiseptics exhibit mucosal cytotoxicity, have a bad flavor, and can cause anaphylactic reactions [54, 56-58]. Therefore, dHC prepared as herbal tea is likely a safer mouthwash than these antiseptics. It also has a milder taste, without odor or cytotoxicity.

The results of our study contribute to the evaluation of $\mathrm{dHC}$ as an effective herbal tea that may help prevent infectious oral diseases. Further studies are needed to fully characterize the constituents of $\mathrm{dHC}$ and identify the specific factors that exhibit the antibiofilm and anti-inflammatory activities. 


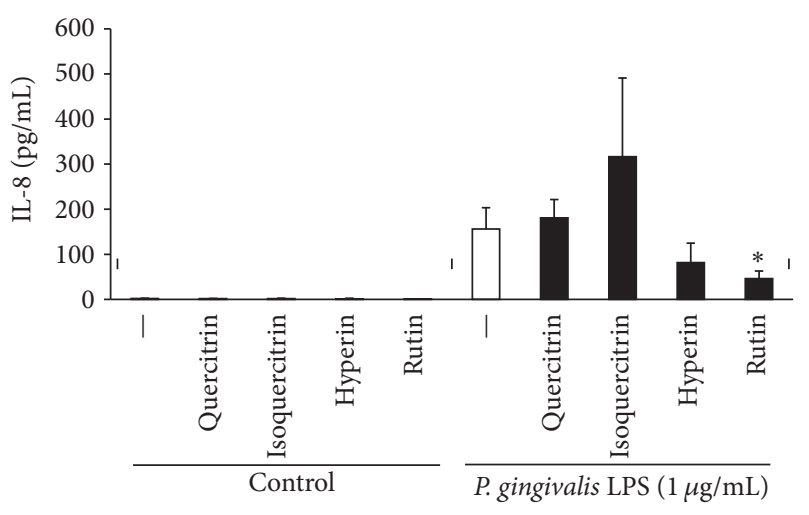

(a)

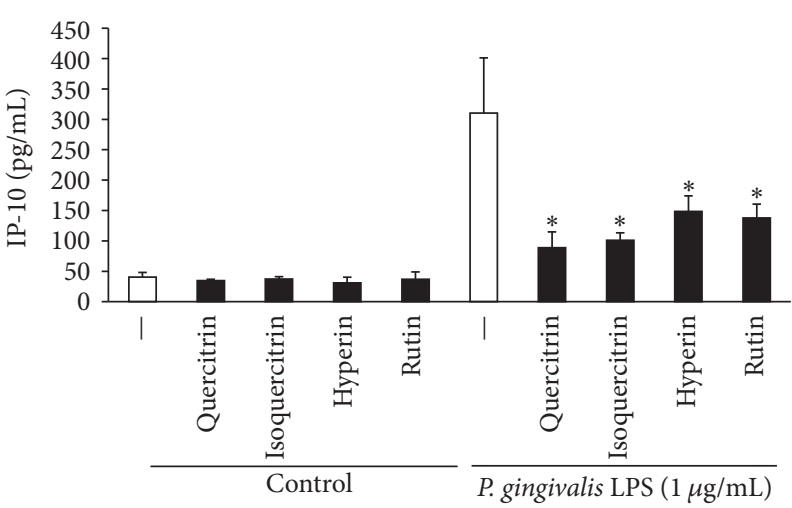

(c)

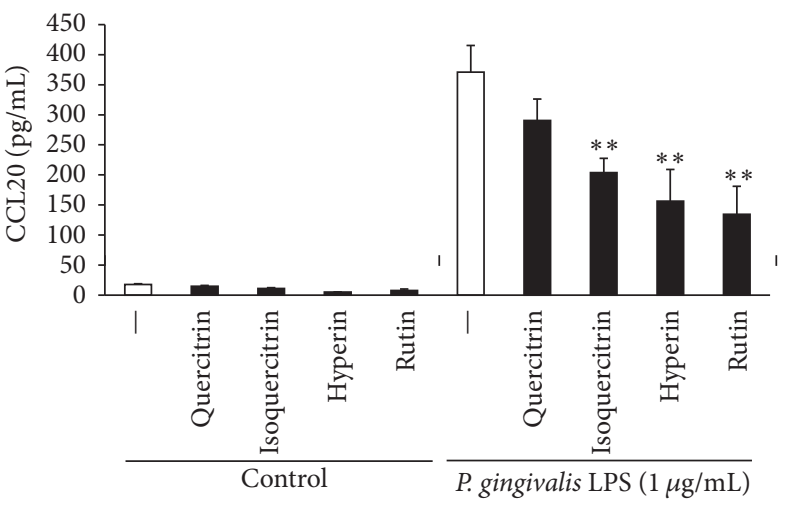

(b)

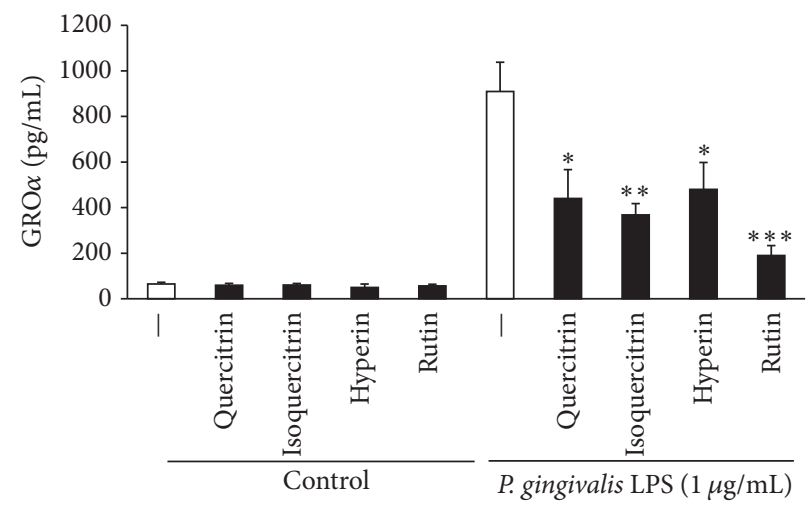

(d)

FIGURE 5: Anti-inflammatory effects of flavonoid glycosides on chemokine production by P. gingivalis LPS-stimulated oral keratinocytes. Inhibitory effects of flavonoid glycosides on IL-8 (a), CCL20 (b), IP-10 (c), and GRO $\alpha$ (d) productions by oral keratinocytes stimulated with $P$. gingivalis LPS for $24 \mathrm{~h} .{ }^{* * *}$ Significant differences between the indicated groups at $p<0.001 .{ }^{* *}$ Significant differences between the indicated groups at $p<0.01$. ${ }^{*}$ Significant differences between the indicated groups at $p<0.05$ using a Student's $t$-test $(n=3)$.

\section{Conclusion}

This study demonstrated that $\mathrm{dHC}$ exerts a moderate antibacterial effect against MRSA and other microorganisms. It also exhibited antibiofilm effects against MRSA, F. nucleatum, and C. albicans. We have shown that $\mathrm{dHC}$ exerts inhibitory effects on IL-8 and CCL20 production by $P$. gingivalis LPS-stimulated human oral keratinocytes, without cytotoxicity. Our results suggest that $\mathrm{dHC}$ has multiple activities in microorganisms and host cells and a herbal tea preparation may be effective in preventing infectious oral diseases.

\section{Conflicts of Interest}

The authors declare that there are no conflicts of interest.

\section{References}

[1] M. Wilson, "Susceptibility of oral bacterial biofilms to antimicrobial agents," Journal of Medical Microbiology, vol. 44, no. 2, pp. 79-87, 1996.

[2] J. W. Costerton, P. S. Stewart, and E. P. Greenberg, "Bacterial biofilms: a common cause of persistent infections," Science, vol. 284, no. 5418, pp. 1318-1322, 1999.
[3] P. E. Kolenbrander, "Oral microbial communities: biofilms, interactions, and genetic systems," Annual Review of Microbiology, vol. 54, pp. 413-437, 2000.

[4] D. R. Radford, S. J. Challacombe, and J. D. Walter, "Denture plaque and adherence of Candida albicans to denture-base materials in vivo and in vitro," Critical Reviews in Oral Biology and Medicine, vol. 10, no. 1, pp. 99-116, 1999.

[5] G. Ramage, K. Tomsett, B. L. Wickes, J. L. López-Ribot, and S. W. Redding, "Denture stomatitis: a role for Candida biofilms," Oral Surgery, Oral Medicine, Oral Pathology, Oral Radiology and Endodontology, vol. 98, no. 1, pp. 53-59, 2004.

[6] K. Hirota, T. Yoneyama, M. Sakamoto et al., "High prevalence of Pseudomonas aeruginosa from oropharyngeal biofilm in patients with cerebrovascular infarction and dysphagia," Chest, vol. 138, no. 1, pp. 237-238, 2010.

[7] E. Martori, R. Ayuso-Montero, J. Martinez-Gomis, M. Viñas, and M. Peraire, "Risk factors for denture-related oral mucosal lesions in a geriatric population," Journal of Prosthetic Dentistry, vol. 111, no. 4, pp. 273-279, 2014.

[8] A. Rekhi, C. M. Marya, S. S. Oberoi, R. Nagpal, C. Dhingra, and S. Kataria, "Periodontal status and oral health-related quality of life in elderly residents of aged care homes," in Proceedings of the in Delhi, Geriatrics Gerontology International, 2015. 
[9] M. P. Cullinan and G. J. Seymour, "Periodontal disease and systemic illness: will the evidence ever be enough?" Periodontology 2000, vol. 62, no. 1, pp. 271-286, 2013.

[10] K. R. Atanasova and Ö. Yilmaz, "Prelude to oral microbes and chronic diseases: past, present and future," Microbes and Infection, vol. 17, no. 7, pp. 473-483, 2015.

[11] M. Wilson, K. Reddi, and B. Henderson, "Cytokine-inducing components of periodontopathogenic bacteria," Journal of Periodontal Research, vol. 31, no. 6, pp. 393-407, 1996.

[12] Y. Kusumoto, H. Hirano, K. Saitoh et al., "Human gingival epithelial cells produce chemotactic factors interleukin-8 and monocyte chemoattractant protein-1 after stimulation with Porphyromonas gingivalis via Toll-like receptor 2," Journal of Periodontology, vol. 75, no. 3, pp. 370-379, 2004.

[13] Y. Taguchi and H. Imai, "Expression of $\beta$-defensin-2 in human gingival epithelial cells in response to challenge with Porphyromonas gingivalis in vitro," Journal of Periodontal Research, vol. 41, no. 4, pp. 334-339, 2006.

[14] R. Schwandner, R. Dziarski, H. Wesche, M. Rothe, and C. J. Kirschning, "Peptidoglycan- and lipoteichoic acid-induced cell activation is mediated by Toll-like receptor 2," Journal of Biological Chemistry, vol. 274, no. 25, pp. 17406-17409, 1999.

[15] Y. Hosokawa, T. Nakanishi, D. Yamaguchi et al., "Macrophage inflammatory protein $3 \alpha$-CC chemokine receptor 6 interactions play an important role in $\mathrm{CD}^{+} \mathrm{T}$-cell accumulation in periodontal diseased tissue," Clinical and Experimental Immunology, vol. 128, no. 3, pp. 548-554, 2002.

[16] L. Ren, W. K. Leung, R. P. Darveau, and L. Jin, “The expression profile of lipopolysaccharide-binding protein, membranebound CD14, and toll-like receptors 2 and 4 in chronic periodontitis," Journal of Periodontology, vol. 76, no. 11, pp. 19501959, 2005.

[17] Y. Takahashi, M. Davey, H. Yumoto, F. C. Gibson III, and C. A. Genco, "Fimbria-dependent activation of pro-inflammatory molecules in Porphyromonas gingivalis infected human aortic endothelial cells," Cellular Microbiology, vol. 8, no. 5, pp. 738757, 2006.

[18] K. Ohta, H. Shigeishi, M. Taki et al., "Regulation of CXCL9/11 in oral keratinocytes and fibroblasts," Journal of Dental Research, vol. 87, no. 12, pp. 1160-1165, 2008.

[19] R. Peyyala, S. S. Kirakodu, K. F. Novak, and J. L. Ebersole, "Oral microbial biofilm stimulation of epithelial cell responses," Cytokine, vol. 58, no. 1, pp. 65-72, 2012.

[20] A. Fukui, K. Ohta, H. Nishi et al., "Interleukin-8 and CXCL10 expression in oral keratinocytes and fibroblasts via toll-like receptors," Microbiology and Immunology, vol. 57, no. 3, pp. 198206, 2013

[21] S. W. Hong, J. E. Baik, S.-S. Kang, C.-H. Yun, D.-G. Seo, and S. H. Han, "Lipoteichoic acid of Streptococcus mutans interacts with Toll-like receptor 2 through the lipid moiety for induction of inflammatory mediators in murine macrophages," Molecular Immunology, vol. 57, no. 2, pp. 284-291, 2014.

[22] G. Ramage, D. F. Lappin, E. Millhouse et al., "The epithelial cell response to health and disease associated oral biofilm models," Journal of Periodontal Research, vol. 52, no. 3, pp. 325-333, 2017.

[23] L. Cai and C. D. Wu, "Compounds from Syzygium aromaticum possessing growth inhibitory activity against oral pathogens," Journal of Natural Products, vol. 59, no. 10, pp. 987-990, 1996.

[24] J.-H. Song, S.-K. Kim, K.-W. Chang, S.-K. Han, H.-K. Yi, and J.G. Jeon, "In vitro inhibitory effects of Polygonum cuspidatum on bacterial viability and virulence factors of Streptococcus mutans and Streptococcus sobrinus," Archives of Oral Biology, vol. 51, no. 12, pp. 1131-1140, 2006.

[25] S.-H. Ban, Y.-R. Kwon, S. Pandit, Y.-S. Lee, H.-K. Yi, and J.-G. Jeon, "Effects of a bio-assay guided fraction from Polygonum cuspidatum root on the viability, acid production and glucosyltranferase of mutans streptococci," Fitoterapia, vol. 81, no. 1, pp. 30-34, 2010.

[26] B. Kumarasamy, S. Manipal, P. Duraisamy, A. Ahmed, S. P. Mohanaganesh, and C. Jeevika, "Role of aqueous extract of Morinda Citrifolia(Indian Noni) ripe fruits in inhibiting dental caries-causing Streptococcus Mutans and Streptococcus Mitis," Journal of Dentistry, vol. 11, no. 6, pp. 703-710, 2014.

[27] J. Limsong, E. Benjavongkulchai, and J. Kuvatanasuchati, "Inhibitory effect of some herbal extracts on adherence of Streptococcus mutans," Journal of Ethnopharmacology, vol. 92, no. 2-3, pp. 281-289, 2004.

[28] Z. H. A. Rahim and N. Thurairajah, "Scanning electron microscopic study of Piper betle L. leaves extract effect against Streptococcus mutans ATCC 25175," Journal of Applied Oral Science, vol. 19, no. 2, pp. 137-146, 2011.

[29] M.-A. Nordin, W. H. A. W. Harun, and F. A. Razak, "An in vitro study on the anti-adherence effect of Brucea javanica and Piper betle extracts towards oral Candida," Archives of Oral Biology, vol. 58, no. 10, pp. 1335-1342, 2013.

[30] J. Y. Choi, J. A. Lee, J. B. Lee, S. J. Yun, and S. C. Lee, "AntiInflammatory Activity of Houttuynia cordata against lipoteichoic acid-induced inflammation in human dermal fibroblasts," Chonnam Medical Journal, vol. 46, no. 3, p. 140, 2010.

[31] H. J. Lee, H.-S. Seo, G.-J. Kim et al., "Houttuynia cordata Thunb inhibits the production of pro-inflammatory cytokines through inhibition of the $\mathrm{NF} \kappa \mathrm{B}$ signaling pathway in HMC-1 human mast cells," Molecular Medicine Reports, vol. 8, no. 3, pp. 731736, 2013.

[32] J. H. Lee, J. Ahn, J. W. Kim, S. G. Lee, and H. P. Kim, “Flavonoids from the aerial parts of Houttuynia cordata attenuate lung inflammation in mice," Archives of Pharmacal Research, vol. 38, no. 7, pp. 1304-1311, 2015.

[33] S. Satthakarn, W. Chung, A. Promsong, and W. Nittayananta, "Houttuynia cordata modulates oral innate immune mediators: Potential role of herbal plant on oral health," Oral Diseases, vol. 21, no. 4, pp. 512-518, 2015.

[34] Y. Sekita, K. Murakami, H. Yumoto et al., "Anti-bacterial and anti-inflammatory effects of ethanol extract from Houttuynia cordata poultice," Bioscience, Biotechnology, and Biochemistry, vol. 80, no. 6, pp. 1205-1213, 2016.

[35] D. W. Lachenmeier, "Safety evaluation of topical applications of ethanol on the skin and inside the oral cavity," Journal of Occupational Medicine and Toxicology, vol. 3, no. 1, article 26, 2008.

[36] Y. Sekita, K. Murakami, H. Yumoto et al., "Preventive effects of Houttuynia cordata extract for oral infectious diseases," BioMed Research International, vol. 2016, Article ID 2581876, 2016.

[37] N. Tanaka, Y. Kashiwada, T. Nakano et al., "Chromone and chromanone glucosides from Hypericum sikokumontanum and their anti-Helicobacter pylori activities," Phytochemistry, vol. 70, no. 1, pp. 141-146, 2009.

[38] Methods for dilution antimicrobial susceptibility tests for bacteria that grow aerobically, s Institute, 8th edition, 2009.

[39] D. A. Hogan, Å. Vik, and R. Kolter, "A Pseudomonas aeruginosa quorum-sensing molecule influences Candida albicans morphology," Molecular Microbiology, vol. 54, no. 5, pp. 1212-1223, 2004. 
[40] A. Nur, K. Hirota, H. Yumoto et al., "Effects of extracellular DNA and DNA-binding protein on the development of a Streptococcus intermedius biofilm," Journal of Applied Microbiology, vol. 115, no. 1, pp. 260-270, 2013.

[41] J. Latimer, J. L. Munday, K. M. Buzza, S. Forbes, P. K. Sreenivasan, and A. J. McBain, "Antibacterial and anti-biofilm activity of mouthrinses containing cetylpyridinium chloride and sodium fluoride," BMC Microbiology, vol. 15, no. 1, article no. 169, 2015.

[42] R. Fujimoto, N. Kamata, K. Yokoyama et al., "Establishment of immortalized human oral keratinocytes by gene transfer of a telomerase component," Journal of Japanese Society for Oral Mucous Membrane, vol. 8, no. 1, pp. 1-8, 2002.

[43] Y. Yoshijima, K. Murakami, S. Kayama et al., "Effect of substrate surface hydrophobicity on the adherence of yeast and hyphal Candida: original article," Mycoses, vol. 53, no. 3, pp. 221-226, 2010.

[44] A. Yoshida, M. Niki, Y. Yamamoto, A. Yasunaga, and T. Ansai, "Proteome analysis identifies the Dpr protein of Streptococcus mutans as an important factor in the presence of early streptococcal colonizers of tooth surfaces," PLoS ONE, vol. 10, no. 3, Article ID e0121176, 2015.

[45] O. Takeuchi, K. Hoshino, T. Kawai et al., "Differential roles of TLR2 and TLR4 in recognition of gram-negative and grampositive bacterial cell wall components," Immunity, vol. 11, no. 4, pp. 443-451, 1999.

[46] T. Kawamura, Y. Hisata, K. Okuda et al., "Pharmacognostical studies of Houttuyniae Herba (1). Flavonoid glycosides contents of Houttuynia cordata Thunb.", Natural Medicines, vol. 48, no. 3, pp. 208-212, 1994.

[47] J. Fuse, H. Kanamori, I. Sakamoto, and S. Yahara, "Studies on flavonol glycosides in Houttuynia cordata," Natural Medicines, vol. 48, no. 4, pp. 307-311, 1994.

[48] T. Kosuge, "Structure of an Antimicrobial Substance isolated from Houttuynia cordata Thunb," Yakugaku Zasshi, vol. 72, no. 10, pp. 1227-1231, 1952.

[49] H. Lu, X. Wu, Y. Liang, and J. Zhang, "Variation in chemical composition and antibacterial activities of essential oils from two species of Houttuynia THUNB," Chemical and Pharmaceutical Bulletin, vol. 54, no. 7, pp. 936-940, 2006.

[50] T. Oyanagi, J. Tagami, and K. Matin, "Potentials of mouthwashes in disinfecting cariogenic bacteria and biofilms leading to inhibition of caries," Open Dentistry Journal, vol. 6, no. 1, pp. 23-30, 2012.

[51] H. Mahmoud Hashemi, F. Mohammadi, M. Hasheminasab, A. Mahmoud Hashemi, S. Zahraei, and T. Mahmoud Hashemi, "Effect of Low-Concentration Povidone Iodine on Postoperative Complications After Third Molar Surgery: A Pilot SplitMouth Study," Journal of Oral and Maxillofacial Surgery, vol. 73, no. 1, pp. 18-21, 2015.

[52] J. Kanagalingam, R. Feliciano, J. H. Hah, H. Labib, T. A. Le, and J.-C. Lin, "Practical use of povidone-iodine antiseptic in the maintenance of oral health and in the prevention and treatment of common oropharyngeal infections," International Journal of Clinical Practice, vol. 69, no. 11, pp. 1247-1256, 2015.

[53] C. Mor-Reinoso, A. Pascual, J. Nart, and M. Quirynen, "Inhibition of de novo plaque growth by a new $0.03 \%$ chlorhexidine mouth rinse formulation applying a non-brushing model: a randomized, double blind clinical trial," Clinical Oral Investigations, vol. 20, no. 7, pp. 1459-1467, 2016.
[54] F. Sadat Sajadi, M. Moradi, A. Pardakhty, R. Yazdizadeh, and F. Madani, "Effect of Fluoride, Chlorhexidine and Fluoridechlorhexidine Mouthwashes on Salivary Streptococcus mutans Count and the Prevalence of Oral Side Effects," Journal of Dental Research, Dental Clinics, Dental Prospects, vol. 9, no. 1, pp. 4952, 2015.

[55] Y. Iwamura, J.-I. Hayashi, T. Sato et al., "Assessment of oral malodor and tonsillar microbiota after gargling with benzethonium chloride," Journal of Oral Science, vol. 58, no. 1, pp. 83-91, 2016.

[56] H. Nagamune, T. Maeda, K. Ohkura, K. Yamamoto, M. Nakajima, and H. Kourai, "Evaluation of the cytotoxic effects of bisquaternary ammonium antimicrobial reagents on human cells," Toxicology in Vitro, vol. 14, no. 2, pp. 139-147, 2000.

[57] P. Chen, W. Huda, and N. Levy, "Chlorhexidine anaphylaxis: Implications for post-resuscitation management," Anaesthesia, vol. 71, no. 2, pp. 242-243, 2016.

[58] G. Sharp, S. Green, and M. Rose, "Chlorhexidine-induced anaphylaxis in surgical patients: A review of the literature," ANZ Journal of Surgery, vol. 86, no. 4, pp. 237-243, 2016. 


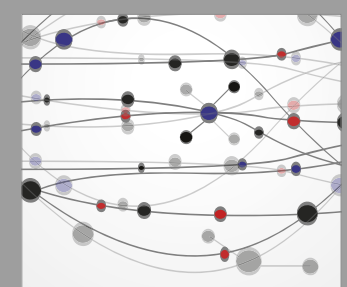

The Scientific World Journal
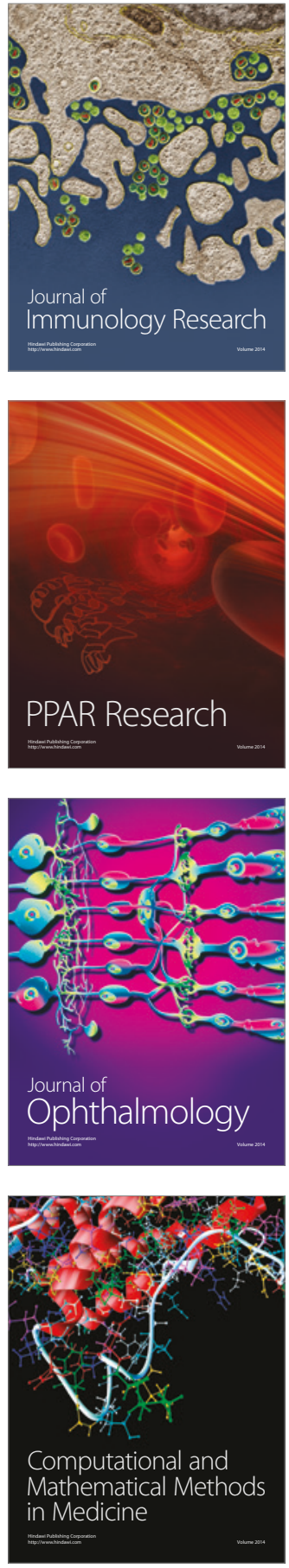

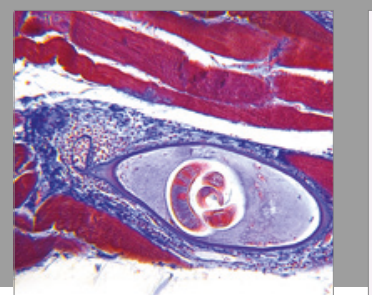

Gastroenterology Research and Practice
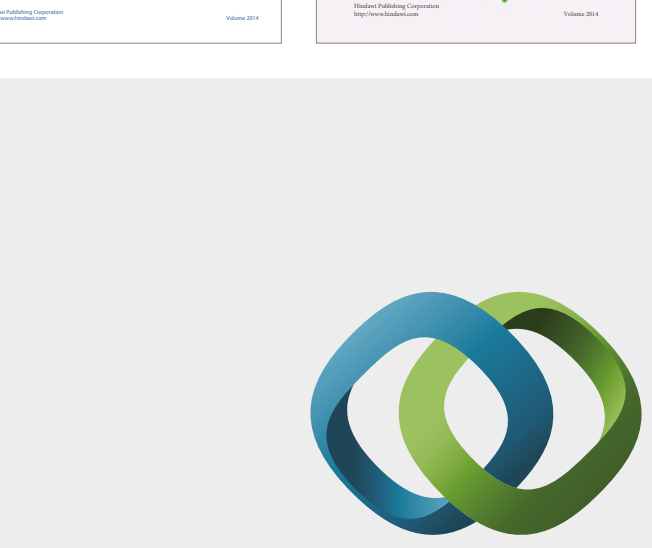

\section{Hindawi}

Submit your manuscripts at

https://www.hindawi.com
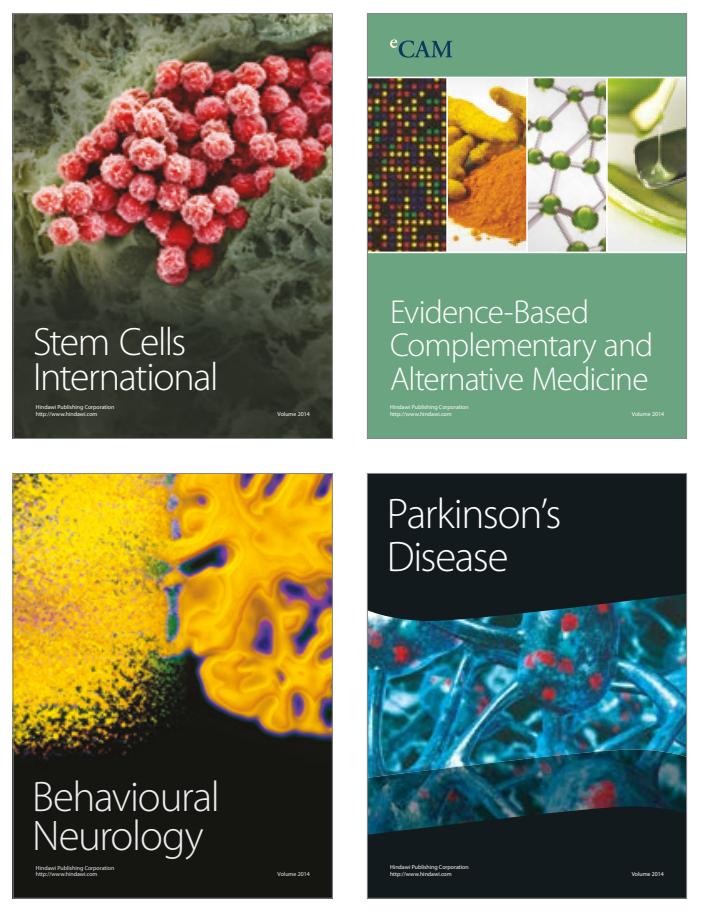
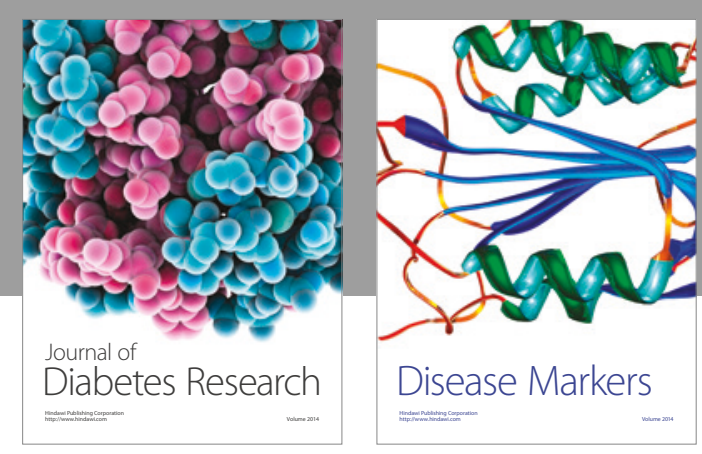

Disease Markers
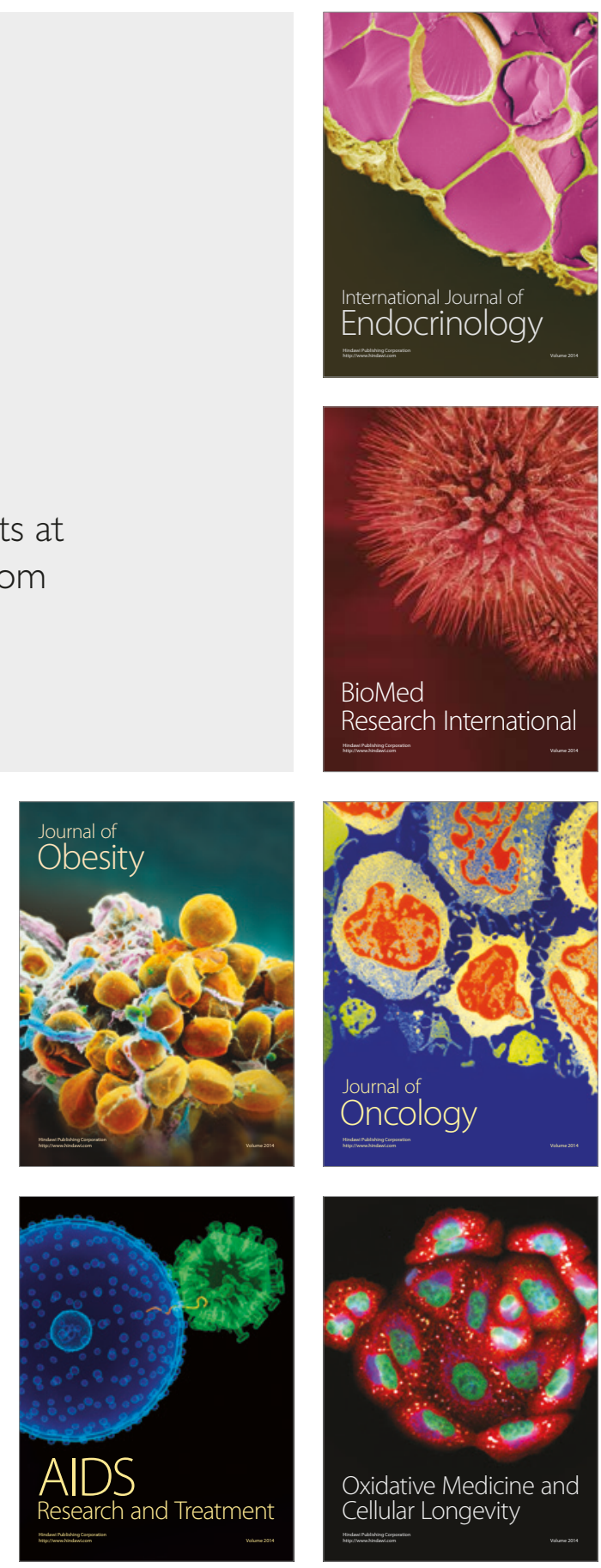